\title{
Universiteit
}

Leiden

The Netherlands

\section{Repeated cervical length measurements for the verification of short cervical length}

Hermans, F.J.R.; Koullali, B.; Os, M.A. van; Ven, J.E.M. van der; Kazemier, B.M.; Woiski, M.D.; ... ; Triple P Grp

\section{Citation}

Hermans, F. J. R., Koullali, B., Os, M. A. van, Ven, J. E. M. van der, Kazemier, B. M., Woiski, M. D., ... Mol, B. W. J. (2017). Repeated cervical length measurements for the verification of short cervical length. International Journal Of Gynecology \& Obstetrics, 139(3), 318-323. doi:10.1002/ijgo.12321

Version: $\quad$ Not Applicable (or Unknown)

License: $\quad$ Leiden University Non-exclusive license

Downloaded from: https://hdl.handle.net/1887/95266

Note: To cite this publication please use the final published version (if applicable). 


\title{
Repeated cervical length measurements for the verification of short cervical length
}

\author{
Frederik J.R. Hermans ${ }^{1, *}$ | Bouchra Koullali ${ }^{1}$ | Melanie A.van Os ${ }^{2}$ | \\ Jeanine E.M. van der Ven ${ }^{1}$ | Brenda M. Kazemier ${ }^{1}$ | Mallory D. Woiski ${ }^{3}$ | \\ Christine Willekes $^{4}$ | Petra N. Kuiper ${ }^{5}$ | Frans J.M.E. Roumen ${ }^{6}$ | \\ Christianne M. de Groot ${ }^{2}$ | Esteriek de Miranda ${ }^{1}$ | Corine Verhoeven ${ }^{7,8}$ | \\ Monique C. Haak ${ }^{9}$ | Eva Pajkrt ${ }^{1}$ | Ewoud Schuit ${ }^{10}$ | Ben Willem J. Mol ${ }^{11}$ | \\ on behalf of the Triple $\mathrm{P}$ group
}

${ }^{1}$ Department of Obstetrics and

Gynecology, Academic Medical Center,

Amsterdam, Netherlands

${ }^{2}$ Department of Obstetrics and

Gynecology, VU University Medical Center,

Amsterdam, Netherlands

${ }^{3}$ Department of Obstetrics and

Gynecology, Radboud University Medical

Center, Nijmegen, Netherlands

${ }^{4}$ Department of Obstetrics and

Gynecology, Maastricht University Medical

Center, Maastricht, Netherlands

${ }^{5}$ Obstetrics and Prenatal Centre FARA,

Ede, Netherlands

${ }^{6}$ Department of Obstetrics and

Gynecology, Atrium Medical Center,

Heerlen, Netherlands

${ }^{7}$ Midwifery Science, AVAG, Amsterdam Public Health Research Institute, VU University

Medical Center, Amsterdam, Netherlands

${ }^{8}$ Department of Obstetrics and

Gynecology, Máxima Medical Center,

Veldhoven, Netherlands

${ }^{9}$ Department of Obstetrics and

Gynecology, Leiden University Medical Center, Leiden, Netherlands

${ }^{10}$ Julius Center for Healthcare Research and Primary Care, University Medical Center Utrecht, Utrecht, Netherlands

${ }^{11}$ The Robinson Research Institute, School of Medicine, University of Adelaide, Adelaide,

SA, Australia

\section{${ }^{*}$ Correspondence}

Frederik J.R. Hermans, Academic Medical Center, Department of Obstetrics and Gynecology, Amsterdam, Netherlands.

Email: f.j.hermans@amc.uva.nl

\section{Abstract}

Objective: To determine if the verification of short cervical length with a repeated measurement improved the identification of patients with short cervical length at increased risk of preterm delivery.

Methods: The present secondary analysis analyzed prospective cohort study data from patients with singleton pregnancies without a history of preterm delivery who presented for obstetric care in the Netherlands and delivered between November 18 , 2009, and January 1, 2013. Cervical length was measured during standard anomaly scan and a second measurement was performed if the cervical length was $30 \mathrm{~mm}$ of shorter. Logistic regression and Cox proportional hazards modeling were used to evaluate associations between cervical length measurements and spontaneous preterm delivery before 37 weeks of pregnancy.

Results: Cervical length measurements from 12358 patients were included; 221 (1.8\%) had an initial cervical length measurement of $30 \mathrm{~mm}$ or shorter. A second cervical length measurement was performed for 167 (75.6\%) patients; no differences were identified in the odds of spontaneous preterm delivery when evaluated using the first, second, or a mean of both measurements, regardless of whether cervical length was analyzed as a continuous or dichotomous variable.

Conclusion: Among patients with singleton pregnancies, verification of short cervical length did not improve the identification of short cervical length.

\section{KEYWORDS}

Cervical length; Preterm delivery; Risk prediction; Singleton pregnancy; Transvaginal ultrasonography; Verification 


\section{INTRODUCTION}

Preterm delivery, defined as delivery before 37 weeks of pregnancy, is a leading contributor to neonatal morbidity and mortality ${ }^{1,2}$ Within the Netherlands, the rate of spontaneous preterm delivery of singleton pregnancies is $5.4 \% .^{3,4}$ Cervical length is an important predictor of spontaneous preterm delivery ${ }^{5,6}$ and studies have demonstrated that mid-trimester asymptomatic short cervical length is associated with an increased risk of spontaneous preterm delivery. ${ }^{6,7}$ Cervicallength measurement by transvaginal ultrasonography is normally performed during the standard anomaly scan at approximately 20 weeks of pregnancy.

Preterm delivery-risk assessment, based on mid-trimester cervical length, needs to be reliable in light of the considering the clinical consequences and potential changes in pregnancy management for patients with a short cervical length. Currently, cervical-length measurement is performed only once but repeating this measurement to verify short cervical length could increase precision.

Conversely, although transvaginal ultrasonography examinations are well tolerated by patients and the risk of adverse events is low, the invasive nature of cervical-length measurements is an important consideration. Further, referrals for additional ultrasonography examinations are time consuming and costly; consequently, it should be performed only when there is clear benefit. ${ }^{8}$

The objective of the present study was to determine whether verification of short cervical length with a second cervical-length measurement would improve the identification of patients with a short cervical length, who are at increased risk of preterm delivery.

\section{2 | MATERIALS AND METHODS}

The present secondary analysis used data from the Triple P screening study. ${ }^{9}$ This nationwide prospective cohort study recruited patients presenting for obstetric care at all settings in the Netherlands, including primary care, between November 18, 2009, and August 1, 2013. This study included asymptomatic, nulliparous and multiparous patients with singleton pregnancies without a history of spontaneous preterm delivery before 34 weeks of pregnancy. The parent study was approved by the medical ethics committee of the Academic Medical Center, Amsterdam, the Netherlands.

In the parent study, eligible patients were invited to participate in a preterm-delivery screening program to have their cervical length measured during a standard anomaly scan at 16-22 weeks of pregnancy. ${ }^{9}$ This program was designed to identify women at risk of preterm delivery based on a short cervical length, defined as $30 \mathrm{~mm}$ or shorter. Cervical length measurements were performed at ultrasonography centers in the primary care setting, as well as at obstetric departments of secondary and tertiary referral centers that performed ultrasonography examinations in their regions. Prior to participating in the parent study, sonographers performing initial cervical length measurements completed an e-learning module, received clinical training to perform cervical length measurements, and had to send five cervical length measurements to be judged by an expert panel, as described in detail previously. ${ }^{10}$

All patients who had a cervical length of $30 \mathrm{~mm}$ or shorter were offered a second cervical length measurement within 14 days at a secondary or tertiary referral center for verification of short cervical length and for a quality control assessment that was necessary owing to transvaginal cervical length measurement not being incorporated in routine care at the onset of the study. Full protocol details have been published previously. ${ }^{9,11}$

Data from the parent study files were linked to the Netherlands Perinatal Registry (http://www.prn.nl) to obtain pregnancy outcomes for these participants and their children. At the time of the present analysis, all pregnancy outcomes until January 1, 2013, were available in the Netherlands Perinatal Registry. Consequently, all participants who had a cervical length measurement up to August 1, 2012, were selected to avoid any confounding by pregnancy outcomes of patients with an expected due date beyond January 1, 2013.

For the present analyses, all women with a primary cervical length measurement of $30 \mathrm{~mm}$ or less at the standard anomaly scan were included. To ensure a heterogeneous population, patients with cervical length measurement made prior to 16 weeks of pregnancy or beyond 22 weeks were included, as were patients with fetuses with congenital anomalies. These data were collected prior to exclusion from the parent study and, consequently, were available for inclusion in the present analysis.

The first and second cervical length measurements, and a mean of both, were analyzed on a continuous scale to prevent loss of information from dichotomization. ${ }^{12,13}$ Cervical length was also analyzed as a dichotomous variable to generate a clinical-applicable cut-off value owing to clinical management using continuous information being potentially challenging. The second measurement was categorized as positive verification $(\leq 30 \mathrm{~mm}$ ) or negative verification (>30 mm); patients who did not receive a second measurement were not excluded but were analyzed as a separate group (classified as verification not performed). These groups of patients were compared with patients who had initial cervical-length measurements longer than $30 \mathrm{~mm}$. Linear regression analysis was used to determine if the time between the measurements was associated with differences in cervical length measurements.

A logistic regression was used to calculate the predicted risk of spontaneous preterm delivery before 37 weeks of pregnancy using cervical length as a continuous variable. Subsequently, predicted risks were plotted against cervical length and the discriminative ability of cervical length was assessed using the area under the receiveroperating-characteristic curve.

Unadjusted and adjusted logistic models were fitted to assess relations between cervical length as a dichotomous variable and spontaneous preterm delivery before 37 weeks of pregnancy. The adjusted model included the following well-known risk factors for spontaneous preterm delivery: parity, use of assisted reproductive technologies, and hypertensive disorders. ${ }^{14}$

Unadjusted and adjusted time-to-event analyses with Cox proportional hazards models were then used to investigate associations between cervical length and time to delivery. The adjusted model 
included the same variables as the previously described logistic model. Patients who had iatrogenic onset of labor and those who delivered at or beyond 37 weeks of pregnancy were excluded from this analysis.

A sensitivity analysis was performed by excluding women carrying fetuses with congenital anomalies and women with a cervical length measured prior to 16 weeks of pregnancy or later than 22 weeks.

All analyses were performed with SPSS version 21.0 (IBM corporation, Armonk, New York, USA) and $P<0.05$ was considered statistically significant.

\section{3 | RESULTS}

A total of 20234 women underwent screening in the Triple P study (between November 1, 2009, and August 1, 2013). Up to January 1, 2013, 12360 of 16204 records with pregnancy outcomes could be linked through the Netherlands Perinatal Registry. There were two patients excluded; one owing to missing cervical length data and one because of an unknown date of delivery, resulting in a cohort of 12358 patients in the present analysis.

The mean \pm SD maternal age at initial cervical length measurement was $31 \pm 4.7$ years, the median cervical length was $43 \mathrm{~mm}$ (interquartile range [IQR] 39-49), there were 5919 (47.9\%) patients who were nulliparous, the median pregnancy duration at delivery was 39 weeks (IQR 38-40), and 493 (4.0\%) patients experienced spontaneous preterm delivery earlier than 37 weeks of pregnancy (Table 1).

There were 221 (1.8\%) patients with a first cervical length measurement of $30 \mathrm{~mm}$ or shorter, and a second measurement was taken for 167 (75.6\%) of these patients. The median cervical length among patients with a short cervical measurement was 28 mm (IQR 25-29) for the first measurements made and $30 \mathrm{~mm}$ (IQR 27-34) for the second measurements. Among the patients who had second cervical length measurements taken, 84 (50.3\%) had second measurements of $30 \mathrm{~mm}$ or shorter. The median difference between the first and second cervical length measurements was $4.0 \mathrm{~mm}$ (IQR 2.0-8.0) and the median interval between measurements was 7 days (IQR 4.0-13.0).

The predicted risks of spontaneous preterm delivery were plotted against cervical length (Fig. 1). As demonstrated by the overlying lines in the plots, no differences were found in predicted risks for spontaneous preterm delivery before 37 weeks of pregnancy when the first, second, or mean of both cervical length measurements were used. This was further confirmed by the comparable discriminative ability of cervical length in predicting preterm delivery using the first, second, or mean of both measurements, with areas under the receiver operating characteristic curves of 0.69 ( $95 \%$ confidence interval [CI] 0.57-0.80), 0.67 (95\% Cl 0.57-0.78), and 0.70 ( $95 \% \mathrm{Cl} 0.59-0.81$ ), respectively.

The odds of spontaneous preterm delivery decreased in line with increasing cervical length for the first, second, or mean of both measurements, with unadjusted odds ratios (ORs) of 0.85 (95\% Cl 0.790.92), 0.91 (95\% Cl 0.87-0.96), and 0.88 (95\% Cl 0.82-0.93) per 1 -mm increase in cervical length, respectively. Adjustment for known preterm delivery risk factors did not alter these results (Table 2).
TABLE 1 Baseline characteristics. ${ }^{a}$

\begin{tabular}{|c|c|c|}
\hline Variable & $\begin{array}{l}\text { Total cohort } \\
(n=12358)\end{array}$ & $\begin{array}{l}\text { Patients with a } \\
\text { first cervical } \\
\text { length } \leq 30 \mathrm{~mm} \\
(\mathrm{n}=221 \text { ) }\end{array}$ \\
\hline Maternal age, y & $31 \pm 4.7$ & $30 \pm 5.0$ \\
\hline Nulliparous & $5919(47.9)$ & $130(58.8)$ \\
\hline White ethnicity & $10290(83.3)$ & $160(72.4)$ \\
\hline Low social economic status & $3214(26.0)$ & $51(23.1)$ \\
\hline Current smoker & $45(0.4)$ & $1(0.5)$ \\
\hline $\begin{array}{l}\text { Assisted reproductive } \\
\text { technology-facilitate } \\
\text { pregnancy }\end{array}$ & $655(5.3)$ & $16(7.2)$ \\
\hline $\begin{array}{l}\text { Pregnancy duration at first } \\
\text { cervical measurement, wk } \\
\text { (range) }\end{array}$ & $20.3 \pm 0.7(16-27)$ & $20.3 \pm 0.8(16-23)$ \\
\hline \multicolumn{3}{|l|}{$\begin{array}{l}\text { First cervical length } \\
\text { measurement }\end{array}$} \\
\hline Cervical length, mm & $43(39-49)$ & $28(25-29)$ \\
\hline Cervical length $\leq 30 \mathrm{~mm}$ & $221(1.8)$ & $221(100.0)$ \\
\hline \multicolumn{3}{|l|}{$\begin{array}{l}\text { Second cervical length } \\
\text { measurement }(n=167)\end{array}$} \\
\hline Measurement interval, d & & $7.0(4.0-13.0)$ \\
\hline Cervical length, mm & & $30(27-34)$ \\
\hline Cervical length $\leq 30 \mathrm{~mm}$ & & $84(50.3)$ \\
\hline $\begin{array}{l}\text { Difference between } \\
\text { measurements, mm }\end{array}$ & & $4.0(2.0-8.0)$ \\
\hline $\begin{array}{l}\text { Mean cervical length } \\
\leq 30 \mathrm{~mm}\end{array}$ & & $112(67.1)$ \\
\hline $\begin{array}{l}\text { Pregnancy duration at } \\
\text { delivery, wk }\end{array}$ & $39(38-40)$ & $39(37-40)$ \\
\hline Hypertensive disorders & $655(5.3)$ & $19(8.6)$ \\
\hline $\begin{array}{l}\text { Spontaneous preterm } \\
\text { delivery at <37 wk of } \\
\text { pregnancy }\end{array}$ & $493(4.0)$ & $39(17.6)$ \\
\hline
\end{tabular}

${ }^{a}$ Values are given as mean $\pm S D$, number (percentage), mean \pm SD (range), or median (interquartile range).

Comparable associations were observed between cervical length and time-to-delivery with hazard ratios for spontaneous preterm delivery before 37 weeks of $0.86(95 \% \mathrm{Cl} 0.81-0.91), 0.92(95 \% \mathrm{Cl}$ $0.89-0.96)$, and $0.88(95 \% \mathrm{Cl} 0.84-0.93)$ per $1-\mathrm{mm}$ increase in cervical length for the first, second, and mean of both measurements, respectively (Table 3). Again, adjustment for known preterm delivery risk factors did not alter these results.

Among patients with an initial cervical measurement of $30 \mathrm{~mm}$ or shorter, $39(17.6 \%)$ had spontaneous preterm deliveries prior to 37 weeks of pregnancy. Patients with initial cervical length measurements of $30 \mathrm{~mm}$ or shorter had significantly higher odds of spontaneous preterm delivery before 37 weeks of pregnancy compared with patients with an initial cervical length measurement longer than $30 \mathrm{~mm}$ (OR 4.0, 95\% Cl 2.7-5.9; adjusted OR 3.7, 95\% Cl 2.5-5.6) (Table 4). 


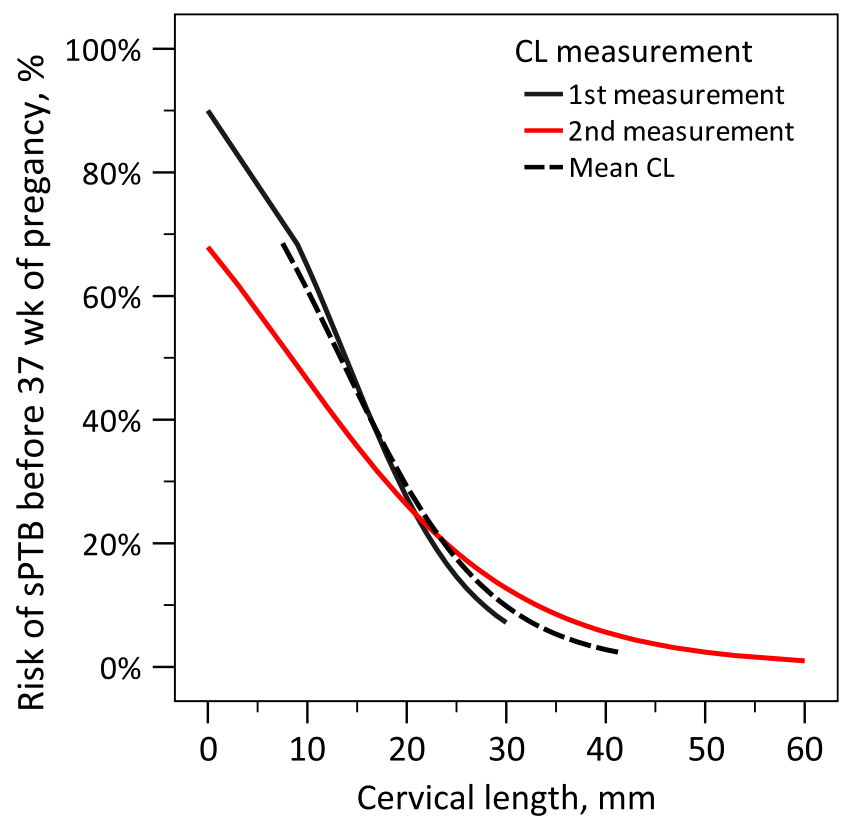

FIGURE 1 Cervical length-predicted risk of sPTD before 37 weeks of pregnancy. Abbreviations: sPTD, spontaneous preterm delivery; $\mathrm{CL}$, cervical length.

An increased risk of spontaneous preterm delivery before 37 weeks was identified among both patients with a positive-verification second measurement (OR 5.9, 95\% Cl 3.0-9.2; adjusted OR 5.2, 95\% $\mathrm{Cl} 3.0-9.2)$ and those with negative-verification second measurements (OR 3.1, 95\% Cl 1.5-6.1; adjusted OR 3.1, 95\% Cl 1.5-6.2) in comparison with patients who had a cervical length above $30 \mathrm{~mm}$ at the initial measurement.

There were 54 (24.4\%) patients with a short cervical length at initial measurement who did not have a second measurement performed. Of these, $5(9 \%)$ had preterm deliveries prior to 37 weeks of pregnancy. This proportion did not differ significantly from women who did have second cervical length measurements $(P=0.171)$. In comparison with patients with initial cervical length measurements above $30 \mathrm{~mm}$, an increased risk of spontaneous preterm delivery before 37 weeks of pregnancy was recorded among patients who did not undergo a second measurement after an initial short measurement (OR $2.6,95 \% \mathrm{Cl}$ 1.02-6.5). However, after adjustment, this association was not significant (adjusted OR 2.5, 95\% Cl 0.97-6.2) (Table 4).

TABLE 2 Association between cervical length and odds of spontaneous preterm delivery before 37 weeks of pregnancy.

\begin{tabular}{lll}
\hline Cervical length (continuous) & $\mathrm{OR}(95 \% \mathrm{Cl})$ & $\mathrm{aOR}^{\mathrm{a}}(95 \% \mathrm{Cl})$ \\
\hline First measurement & $0.85(0.79-0.92)$ & $0.85(0.78-0.93)$ \\
\hline Second measurement & $0.91(0.87-0.96)$ & $0.91(0.86-0.96)$ \\
\hline Mean of both measurements & $0.88(0.82-0.93)$ & $0.87(0.81-0.93)$ \\
\hline
\end{tabular}

Abbreviations: OR, odds ratio; $\mathrm{Cl}$, confidence interval; aOR, adjusted odds ratio.

${ }^{a}$ Adjusted for parity, use of assisted reproductive technologies, and hypertensive disorders.
TABLE 3 Association between cervical length and time-to-delivery.

\begin{tabular}{lll}
\hline Cervical length (continuous) & $\mathrm{HR}(95 \% \mathrm{Cl})$ & $\mathrm{aHR}^{\mathrm{a}}(95 \% \mathrm{Cl})$ \\
\hline First measurement & $0.86(0.81-0.91)$ & $0.86(0.81-0.91)$ \\
\hline Second measurement & $0.92(0.89-0.96)$ & $0.91(0.87-0.95)$ \\
\hline Mean of both measurements & $0.88(0.84-0.93)$ & $0.88(0.83-0.92)$ \\
\hline
\end{tabular}

Abbreviations: $\mathrm{HR}$, hazard ratio; $\mathrm{Cl}$, confidence interval; aHR, adjusted hazard ratio.

${ }^{a}$ Adjusted for parity, use of assisted reproductive technologies, and hypertensive disorders.

The time between both measurements was not associated with a difference in length between the measurements (linear correlation coefficient $-0.012,95 \% \mathrm{Cl}-0.028$ to $0.004 ; P=0.129$ ) or with the risk of positive second-measurement verification (OR $0.998,95 \% \mathrm{Cl}$ 0.993-1.003; $P=0.444)$. Sensitivity analyses that excluded patients carrying fetuses with congenital anomalies $(n=215)$ and those who had cervical length measured before 16 weeks of pregnancy of after 22 weeks of pregnancy $(n=238)$ yielded similar results (Supplemental Tables S1 and S2).

\section{DISCUSSION}

In the present secondary analysis of cervical length measurement, a second cervical measurement to verify short cervical length was not necessary in patients with singleton pregnancies undergoing preterm delivery risk assessment.

A strength of the present study was that the data were collected through a nationwide collaboration of primary and secondary

TABLE 4 Verification of cervical length measurements and risk of spontaneous preterm delivery before 37 weeks of pregnancy.

\begin{tabular}{|c|c|c|c|}
\hline \multirow[b]{2}{*}{ Cervical length } & \multirow{2}{*}{$\begin{array}{l}\text { Preterm } \\
\text { delivery } \\
<37 \text { wk of } \\
\text { pregnancy }^{a}\end{array}$} & \multicolumn{2}{|c|}{$\begin{array}{l}\text { Odds of spontaneous } \\
\text { preterm delivery }<37 \mathrm{wk} \\
\text { of pregnancy }^{\mathrm{b}}\end{array}$} \\
\hline & & $\begin{array}{l}\text { OR } \\
(95 \% \mathrm{Cl})\end{array}$ & $\begin{array}{l}\mathrm{aOR}^{\mathrm{c}} \\
(95 \% \mathrm{Cl})\end{array}$ \\
\hline $\begin{array}{l}\text { First cervical measurement } \\
\leq 30 \mathrm{~mm}(\mathrm{n}=221)\end{array}$ & $30(13.6)$ & $4.0(2.7-5.9)$ & $3.7(2.5-5.6)$ \\
\hline \multicolumn{4}{|l|}{$\begin{array}{l}\text { Second cervical } \\
\text { measurement }\end{array}$} \\
\hline$\leq 30 \mathrm{~mm}(\mathrm{n}=84)$ & $16(19)^{d}$ & $5.9(3.0-9.2)$ & $5.2(3.0-9.2)$ \\
\hline$>30 \mathrm{~mm}(\mathrm{n}=83)$ & $9(11)^{d}$ & $3.1(1.5-6.2)$ & $3.1(1.5-6.2)$ \\
\hline Not performed $(n=54)$ & $5(9)^{d}$ & $2.6(1.0-6.5)$ & $2.5(1.0-6.2)$ \\
\hline
\end{tabular}

Abbreviations: $\mathrm{OR}$, odds ratio; $\mathrm{Cl}$, confidence interval; aOR, adjusted odds ratio.

${ }^{a}$ Values given as number (percentage).

b In comparison with patients who had cervical length $>30 \mathrm{~mm}$ at first measurement.

${ }^{c}$ Adjusted for parity, use of assisted reproductive technologies, and hypertensive disorders.

${ }^{\mathrm{d}}$ No significant difference $\left(\chi^{2}\right) ; P=0.171$. 
care within the Dutch Consortium for Women's Health (www.studies-obsgyn.nl). Consequently, the large high-quality cohort of patients with singleton pregnancies represented the Dutch general obstetric population with a representative preterm-delivery rate. ${ }^{3}$ Consequently, it was possible to investigate whether a second cervical length measurement in women with a short cervical length was of added clinical value in risk stratification for preterm delivery. A limitation of the study was that a repeated cervical length measurement was only performed in patients with initial measurements of $30 \mathrm{~mm}$ or shorter and that, in the present study population, a 'dip' of cervical length measurements between 20 and $30 \mathrm{~mm}$ was observed, probably as a result of the fact that assessors were not masked. ${ }^{15}$ Consequently, partial verification bias could have been present. However, this mainly affected women who were incorrectly classified as low-risk; this could only have led to an underestimation of the effect of cervical length on preterm delivery. ${ }^{16}$ Ideally, all primary cervical length measurements would have been repeated; however, this was not the aim of the parent study and, consequently, was logistically impossible in the present analysis. Clinically, the most significant group of patients were those with a short cervical length and it was demonstrated that an additional measurement was not necessary because the risk of preterm delivery was increased in all women with an initial short cervical length, including those who had negative verification and those who did not have a second measurement.

Another issue is whether the interval between measurements could have resulted in differences in cervical length measurements; however, no association was identified between the intervals and measurement differences. Additionally, cervical length shortens throughout pregnancy, primarily during the third trimester, and only approximately $1 \mathrm{~mm}$ per week during the mid-trimester period. ${ }^{17}$

To the best of our knowledge, this was the first study to investigate the clinical value of a second cervical length measurement to verify mid-trimester short cervical length in women with singleton pregnancies who had been diagnosed within any obstetric care setting, including primary care. ${ }^{18,19}$ In the Netherlands, cervical length measurement in asymptomatic singleton pregnancies was not part of standard care at the time of the study. Consequently, the majority of participating sonographers had to learn to perform cervical length measurements. A potential limitation was that this learning curve could result in greater variation between measurements. Cervical length measurement is considered to be a good reproducible measurement when performed by trained ultrasonographers, with an intra- and inter-observer variance of $3-5 \mathrm{~mm} .^{20,21}$ This is comparable to the present study, where the median difference between measurements was $4 \mathrm{~mm}$. Additionally, participating sonographers completed an e-learning module and were trained in cervical length measurements to improve the quality of the measurements. ${ }^{11}$

In general, whether the reported inter- and intra-observer variances are acceptable can be debated; in clinical practice, a smaller change in cervical length than the inter- and intra-observer variance can already result in a change in risk classification. This would be most likely to happen when a dichotomous cut-off value $(30 \mathrm{~mm})$ is used. Further, when multiple measurements are performed, the phenomenon of regression to the mean-when extreme values tend to change towards their mean-also plays a role. It is not known if changes in risk stratification are misclassifications; however, it shows that multiple cervical length measurements do not improve accuracy and that a single measurement suffices for this purpose.

Cervical length is an important risk factor for preterm delivery; however, the relative contribution of clinical length to preterm delivery remains unclear, mainly because the prevalence of short cervical length is low and not all women with a short cervical length will deliver preterm. Conversely, promising treatments are available to prevent preterm delivery in women with a short cervical length that stimulate cervical length screening programs for the prevention of preterm delivery. ${ }^{22,23}$

Further research should focus on the properties and dynamics of cervical length throughout pregnancy to determine optimal risk classification to better identify women at risk for preterm delivery based on cervical length. Additionally, attempts to improve the accuracy of cervical length measurements should be made by following the recommended criteria for cervical length measurement more strictly, with the aim of minimizing measurement errors that can lead to the misclassification of patients. ${ }^{24}$

The present study demonstrated that a second cervical length measurement to verify a length of $30 \mathrm{~mm}$ or shorter during standard anomaly scan is not currently necessary; it does not further improve the identification of patients who are at increased risk of preterm delivery.

\section{AUTHOR CONTRIBUTIONS}

FJRH contributed to designing the study, performing and interpreting the analysis, and writing and revising the manuscript. BK contributed to designing the study, interpreting the analysis, and writing and revising the manuscript. MAvO, JEMvV, BMK, MDW, CW, PNK, FJMER, $\mathrm{CMdG}$, EdM, CV, and $\mathrm{MCH}$ contributed to interpreting the analysis and revising the manuscript. EP contributed to designing the study and writing the manuscript. ES contributed to designing the study, performing and interpreting the analysis, and revising the manuscript. BWJM contributed to designing the study and writing the manuscript.

\section{CONFLICTS OF INTEREST}

The authors have no conflicts of interest.

\section{REFERENCES}

1. Goldenberg RL, Culhane JF, lams JD, Romero R. Epidemiology and causes of preterm birth. Lancet. 2008;371:75-84.

2. Slattery MM, Morrison JJ. Preterm delivery. Lancet. 2002;360: 1489-1497.

3. Schaaf JM, Mol BWJ, Abu-Hanna A, Ravelli ACJ. Trends in preterm birth: Singleton and multiple pregnancies in the Netherlands, 20002007. BJOG. 2011;118:1196-1204.

4. EURO-PERISTAT Project. Health and care of pregnant women and babies in Europe in 2010. 2013 
5. Honest H, Bachmann LM, Coomarasamy A, Gupta JK, Kleijnen J, Khan KS. Accuracy of cervical transvaginal sonography in predicting preterm birth: A systematic review. Ultrasound Obstet Gynecol. 2003;22:305-322.

6. lams JD, Goldenberg RL, Meis PJ, et al. The length of the cervix and the risk of spontaneous premature delivery. National Institute of Child Health and Human Development Maternal Fetal Medicine Unit Network. N Engl J Med. 1996;334:567-572.

7. Heath VC, Southall TR, Souka AP, Elisseou A, Nicolaides KH. Cervical length at 23 weeks of gestation: Prediction of spontaneous preterm delivery. Ultrasound Obstet Gynecol. 1998;12:312-317.

8. Dutta RL, Economides DL. Patient acceptance of transvaginal sonography in the early pregnancy unit setting. Ultrasound Obstet Gynecol. 2003;22:503-507.

9. van der Ven J, van Os MA, Kazemier BM, et al. The capacity of mid-pregnancy cervical length to predict preterm birth in lowrisk women: A national cohort study. Acta Obstet Gynecol Scand. 2015;94:1223-1234.

10. van Os MA, van der Ven AJ, Bloemendaal PM, et al. Effect of e-learning on quality of cervical-length measurements. Ultrasound Obstet Gynecol. 2015;46:327-331.

11. van Os MA, van der Ven JA, Kleinrouweler CE, et al. Preventing preterm birth with progesterone: Costs and effects of screening low risk women with a singleton pregnancy for short cervical length, the Triple P study. BMC Pregnancy Childbirth. 2011;11:77.

12. Altman DG, Royston P. The cost of dichotomising continuous variables. BMJ. 2006;332:1080.

13. lams JD, Johnson FF, Sonek J, Sachs L, Gebauer C, Samuels P. Cervical competence as a continuum: A study of ultrasonographic cervical length and obstetric performance. Am J Obstet Gynecol. 1995;172:1097-1103-6.

14. Davies EL, Bell JS, Bhattacharya S. Preeclampsia and preterm delivery: A population-based case-control study. Hypertens Pregnancy. 2016;35:510-519.

15. van Os MA, Kleinrouweler CE, Schuit E, et al. Influence of cut-off value on prevalence of short cervical length. Ultrasound Obstet Gynecol. 2017;49:330-336.

16. Whiting P, Rutjes AWS, Reitsma JB, Glas AS, Bossuyt PMM, Kleijnen J. Sources of variation and bias in studies of diagnostic accuracy: $A$ systematic review. Ann Intern Med. 2004;140:189-202.
17. Gramellini D, Fieni S, Molina E, Berretta R, Vadora E. Transvaginal sonographic cervical length changes during normal pregnancy. J Ultrasound Med. 2002;21:227-232-5.

18. GrobmanWA,ThomEA,Spong CY, etal.17Alpha-hydroxyprogesterone caproate to prevent prematurity in nulliparas with cervical length less than 30 mm. Am J Obstet Gynecol. 2012;207:390.e1-390.e8.

19. Norman JE, Marlow N, Messow C-M, et al. Vaginal progesterone prophylaxis for preterm birth (the OPPTIMUM study): A multicentre, randomised, double-blind trial. Lancet. 2016;387:2106-2116.

20. Heath VC, Southall TR, Souka AP, Novakov A, Nicolaides KH. Cervical length at 23 weeks of gestation: Relation to demographic characteristics and previous obstetric history. Ultrasound Obstet Gynecol. 1998;12:304-311.

21. Berghella V, Tolosa JE, Kuhlman K, Weiner S, Bolognese RJ, Wapner RJ. Cervical ultrasonography compared with manual examination as a predictor of preterm delivery. Am J Obstet Gynecol. 1997;177:723-730.

22. Goya M, Pratcorona L, Merced C, et al. Cervical pessary in pregnant women with a short cervix (PECEP): An open-label randomised controlled trial. Lancet. 2012;379:1800-1806.

23. Dodd JM, Jones L, Flenady V, Crowther CA, Cincotta R. Prenatal administration of progesterone for preventing preterm birth in women considered to be at risk of preterm birth. Cochrane Database Syst Rev. 2013;7:CD004947.

24. lams JD, Grobman WA, Lozitska A, et al. Adherence to criteria for transvaginal ultrasound imaging and measurement of cervical length. Am J Obstet Gynecol. 2013;209:365.e1-365.e5.

\section{SUPPORTING INFORMATION}

Additional Supporting Information may be found online in the supporting information tab for this article.

Table S1. Sensitivity analysis of association between cervical length and spontaneous preterm delivery before 37 weeks of pregnancy.

Table S2. Sensitivity analysis of verification cervical length measurement and risk of spontaneous preterm delivery before 37 weeks of pregnancy. 